OPEN ACCESS

Edited by: Cirino Botta,

Cosenza Hospital, Italy

Reviewed by:

Vito Carlo Alberto Caponio,

University of Foggia, Italy

Yona Keisari,

Tel Aviv University, Israel

*Correspondence:

Wanzhuo Xie

xiewanzhuo@zju.edu.cn

${ }^{\dagger}$ These authors have contributed equally to this work

Specialty section

This article was submitted to Hematologic Malignancies,

a section of the journa

Frontiers in Oncology

Received: 16 July 2020 Accepted: 23 September 2020 Published: 13 October 2020

Citation:

Zhang $Y$, Zheng $Y$, Shou $L$, Shi $Y$, Shen H, Zhu M, Ye X, Jin J and Xie W

(2020) Increased Serum Level of Interleukin-10 Predicts Poor Survival and Early Recurrence in Patients With

Peripheral T-Cell Lymphomas.

Front. Oncol. 10:584261.

doi: 10.3389/fonc.2020.584261

\section{Increased Serum Level of Interleukin- 10 Predicts Poor Survival and Early Recurrence in Patients With Peripheral T-Cell Lymphomas}

\author{
Yan Zhang ${ }^{1,2 \dagger}$, Yanlong Zheng ${ }^{1 \dagger}$, Lihong Shou ${ }^{2}$, Yuanfei Shi ${ }^{1}$, Huafei Shen ${ }^{1}$, \\ Mingyu Zhu ${ }^{1}$, Xiujin $\mathrm{Ye}^{1}$, Jie Jin ${ }^{1}$ and Wanzhuo Xie ${ }^{1 *}$ \\ ${ }^{1}$ Department of Hematology, The First Affiliated Hospital, College of Medicine, Zhejiang University, Hangzhou, China, \\ 2 Department of Hematology, Huzhou Central Hospital, Affiliated Cent Hospital of Huzhou University, Huzhou, China
}

Peripheral T cell lymphoma (PTCL) is an alloplasm group of aggressive and lymphoproliferative tumors with heterogeneous morphological changes of mature T cell immunophenotype. It has multiple subtypes and most of them have poor prognosis. Interleukin 10 (IL-10) is one kind of multi-cell-derived and multifunctional cytokine. It regulates the growth and differentiation of cells, participates in inflammation and immune response, plays an important role in tumor and infection, and is closely related to blood system diseases. Therefore, we implemented a retrospective study of 205 patients who were newly diagnosed with PTCL to explore the relationship between IL-10 and prognosis and early recurrence. We found patients with IL-10 $\geq 3.6 \mathrm{pg} / \mathrm{ml}$ achieved a lower $\mathrm{CR}$ rate and higher 1 -year recurrence rate than patients with IL$10<3.6$ pg/ml (14.4 vs. 51.9\%; 17.6 vs. 49.5\%). On multivariate analysis, moreover, elevated $\mathrm{IL}-10$ is an extremely important prognostic factor in PTCL, which can lead to worsening of overall survival (OS), low complete response (CR) rate and higher early relapse rate. Therefore, measurement of IL-10 levels in peripheral blood at the initial stage are useful for predicting the prognosis and helping us to make different treatment plans for individual patients. In the near future, IL-10 inhibitors or antagonists may become a new method of immunotargeting therapy for patients with PTCL.

Keywords: peripheral T-cell lymphoma, interleukin-10, complete response, prognosis, early recurrence

\section{INTRODUCTION}

Peripheral T cell lymphoma (PTCL) is a group of rare lymphoid malignancies with heterogeneous morphological that originating from post-thymic $\mathrm{T}$ cells or mature natural killer (NK) cells, accounting for about $10 \%$ of all non-Hodgkin's lymphomas (NHL) in Western countries (1). However, the morbidity of PTCL is higher in Asia, it makes up 25-30\% of NHL in China (2). According to the WHO classification, PTCL can be further distinguished based on their immunophenotypical, morphological, biological, and clinical features (3). The most common subtypes include PTCL-not otherwise specified (PTCL-NOS), extra-nodal natural killer (NK)/T cell lymphoma, nasal type (ENKTL), angioimmunoblastic T-cell lymphoma (AITL), anaplastic large-cell lymphoma (ALCL), include ALCL anaplastic lymphoma kinase positive(ALCL, ALK +), and ALCL anaplastic lymphoma kinase negative 
(ALCL, ALK-). Relatively uncommon subtypes include monomorphic epitheliotropic intestinal T-cell lymphoma (MEITL), T-cell Large Granular Lymphocytic Leukemia (TLGLL), subcutaneous panniculitis like T-cell lymphoma (SPTCL), mycosisfungoides/Sezary's syndrome (MF/SS), Hepatosplenic T-cell lymphoma (HSTCL), and so on. The overall characteristics of them are aggressive clinical course and poor response to therapy. Due to its rarity and heterogeneity, prognostic studies on PTCL are relatively scarce.

The development of science and technology as a whole society has promoted the development of molecular biology and the understanding of PTCL is greatly improved, particularly in tumor micro-environment. Interleukin 10 (IL-10) is one kind of multi-cell-derived and multifunctional cytokine. It regulates the growth and differentiation of cells, participates in inflammation and immune response, plays an important role in tumor and infection, and is closely related to blood system diseases. It is mainly excreted by activated T cells, monocytes, B cells, macrophages, certain tumor cells and so on. Not only that, various studies have shown that IL-10 can promote the development of tumor cells. Studies have shown that some malignant $\mathrm{T}$ cells can grow and survive well, but they are mainly closely related to (M2) macrophages that are alternately activated within the microenvironment. Moreover, IL-10 will have an enhanced effect to some extent (4). In addition, the abnormality of JAK/STAT pathway will promote IL-10mediated lymphoid hyperplasia by M2 macrophages (5). The GATA-binding protein 3 (GATA3) is a transcription factor related to the type 2 helper (Th2) cell. If GATA3 is overexpressed, it will affect the survival rate of PTCL, to be precise, it will reduce the survival rate (6). Not only that, it also induces the expression of Th2-related cytokines, such as IL-10 (7). In this way, IL-10 has more ways to help malignant lymphocytes express genetic material, achieve the purpose of reproduction, and promote immune escape of tumor. Because previous studies had shown that IL-10 is associated with abnormal proliferation of cancer cells in a variety of cancers (breast cancer, cervical cancer, thyroid cancer, etc.) (8-10). Moreover, the role of IL-10 in Hodgkin's lymphoma, diffuse large B-cell lymphoma (DLBCL) and Burkitt's lymphoma had also been extensively studied $(11,12)$. However, little is known about the effects of IL-10 on response and prognosis, especially the early recurrence or progression of PTCL patients. Consequently, we retrospectively analyzed 205 PTCL patients, and aimed to study the significance of IL-10 in their treatment response, survival rate, and early relapse.

The writing of our article refers to the Reporting Recommendations for Tumor Marker Prognostic Studies (REMARK): Explanation and Elaboration guidelines (13).

\section{MATERIALS AND METHODS}

\section{Patients and Control Subjects}

This is a single-center retrospective cohort analysis of 205 newly diagnosed PTCL patients at the First Affiliated Hospital of Zhejiang
University School of Medicine from January 2014 to June 2019. The inclusion criteria for this retrospective study were as follows: (1) Age $\geq 18$ years; (2) Pathological diagnosis of PTCL; (3) No longterm glucocorticoid treatment or chemotherapy before collecting clinical data; (4) Complete Clinical data. According to the Helsinki statement, all patients in our study signed an informed consent form before peripheral blood was drawn. Although the treatment regimens of PTCL patients in our study were inconsistent, most patients received combination chemotherapy, including cyclophosphamide-doxorubicin-vincristine-prednisone (CHOP) or CHOP-like regimens, and all the ENKTL patients' chemotherapy containing Pegaspargase. The final observation time was January 2020, and the median follow-up time was 14 months.

\section{Measurement and Evaluation Indicators}

We reviewed medical records, physical examinations, laboratory results, pathology reports, and radiological findings to reanalyze the clinical data of these patients. The following experimental and clinical data were collected: age at diagnosis, sex, International Prognostic Index (oncology) (IPI) score, Eastern Cooperative Oncology Group (ECOG), Ann Arbor stage, B symptoms (fever, night sweating, or weight loss), serum albumin level, bone marrow involvement, Hemophagocytic syndrome (HPS), serum interleukin-6 level (IL-6), serum interleukin-10 level (IL-10), serum interferon $\gamma$ level (IFN $\gamma$ ), Epstein-Barr virus(EBV) infection, number of involved extranodal sites, serum lactate dehydrogenase (LDH), beta-2 microglobulin( $\beta 2-\mathrm{MG})$ and serum ferritin (SF). Regular imaging examinations were performed after treatment, and disease status were recorded and analyzed. Follow-up was performed by making phone calls or reviewing medical records. Progression was defined as an increase in volume of the original focus or the development of a new focus. Early recurrence was defined as relapse or progressive disease occurrence within 1-year postchemotherapy. OS was defined as the time from diagnosis to death for any reasons or last follow-up.

\section{Detection of Cytokines in Peripheral Blood of Patients}

The levels of cytokines in peripheral blood were detected by CBA (cytomic beam array system) flow cytometry according to the manufacturer's instructions.

\section{Statistical Analysis}

Post hoc power analyses were conducted with GPOWER (Faul, Erdfelder, Lang, \& Buchner, 2007) in order to estimate the probability of occurrence of effects in the sample. The optimal cut-off values of interleukin 10, interleukin 6, and interferon gamma levels were determined by receiver operating characteristic (ROC) curve analysis. They were associated with survival status of patients. Through the normal distribution test, the continuous variables included in this study all conform to the normal distribution. Continuous variables were grouped according to the usual clinical threshold and were presented as frequencies and percentages $(n, \%)$ in company with categorical variables. All hierarchical and categorical variables were 
compared by Pearson's chi-square test. Among them, histological subtypes were performed bonferroni-post-hoccorrection. The survival curve was attained via Kaplan-Meier method and the log-rank test. Univariate and multivariate logistic regression models were used to evaluate the relevance between clinical variables and complete remission (CR) and 1 -year recurrence or progression. Cox proportional hazards regression model was used to analyze univariate and multivariate of OS. All statistical analyses were calculated by statistical software package SPSS 23.0. In all comparisons, $\mathrm{p}<0.05$ was considered to be statistically significant.

\section{RESULTS}

\section{Patients Characteristics and Clinical Outcomes According to the Different Levels of IL-10}

According to the criteria, we selected 205 patients with PTCL from January 2014 to June 2019. Table 1 lists the clinical characteristics and laboratory data of all enrolled patients. The median age at diagnosis was 56 years (range: 18-79 years), and the ratio of male to female was 1.8:1. Eighty point five percent of these patients were in stage III-IV, and $55.1 \%$ of them had B symptoms. ENKTL accounted for $33.6 \%$ of all pathological subtypes, PTCL-NOS, AITL and ALCL accounted for 21.8, 27.5 , and $12.7 \%$ respectively. In addition, there were 68 cases of bone marrow involvement, and 24 cases of HPS. More than one extranodal location was involved in 98 patients, and 120 patients were infected with EBV at the first diagnosis. The serum $\mathrm{LDH}$ levels were increased in $66.3 \%$ of the patients, meanwhile the levels of $\beta 2-\mathrm{MG}$ were increased in $63.9 \%$. According to the IPI risk classification, $54.1 \%$ of patients $(\mathrm{n}=111)$ were at high or high-moderate risk. Table 1 shows the clinical characteristics of patients with different IL-10 levels. It shows that patients with IL10 levels exceeding $3.6 \mathrm{pg} / \mathrm{ml}$ have higher IPI scores and ECOG scores, and the proportion of B symptoms and HPS were significantly higher than those with IL-10 levels less than 3.6 $\mathrm{pg} / \mathrm{ml}$. Patients with IL-10 levels higher than $3.6 \mathrm{pg} / \mathrm{ml}$ had higher proportion of LDH, $\beta 2-\mathrm{MG}$, and SF. However, the different subtypes of PTCL did not show statistical significance in the stratification of IL-10 in our study, either by Pearson's chi square test $(\mathrm{P}=0.287)$ or performing bonferroni-post-hoc$\operatorname{correction}(\mathrm{P}=0.288)$.

\section{Association of Serum Cytokines With Survival Outcome and Early Recurrence}

We had analyzed six cytokines: IL-4, IL-6, IL-10, TNF $\alpha$, IFN $\gamma$, and IL-17A. Only IL-6, IL-10, and IFN $\gamma$ were found to have statistical significance on the survival and prognosis of PTCL patients and the median value and range of serum levels of these three cytokines were as follows: IL-10 $(3.13 \mathrm{pg} / \mathrm{ml}$, range: $0.1-$ $8536.4 \mathrm{pg} / \mathrm{ml}), \mathrm{IL}-6(6.65 \mathrm{pg} / \mathrm{ml}$, range: $0.1-815.2 \mathrm{pg} / \mathrm{ml})$, and IFN- $\gamma(1.44 \mathrm{pg} / \mathrm{ml}$, range: $0-1330.9 \mathrm{pg} / \mathrm{ml})$, respectively. According to the ROC curve, the cutoff values of IL-6, IL-10, and IFN $\gamma$ were determined to be $2.2 \mathrm{pg} / \mathrm{ml}, 3.6 \mathrm{pg} / \mathrm{ml}$ and $3.0 \mathrm{pg} /$ $\mathrm{ml}$, respectively. The area under the curve are $0.572,0.736,0.634$ for the IL-6, IL-10 and IFN $\gamma$ (Figure 1). Therefore, the high group and low group were defined as being greater than or equal to the cutoff value and less than the cutoff value, respectively. Post hoc analysis demonstrated sufficient power to distinguish the significant differences (power $=0.945$ ). Patients with IL-10 $\geq 3.6 \mathrm{pg} / \mathrm{ml}$, only $14.4 \%$ of them achieved CR after treatment, but the rate of recurrence or progression within one year was nearly half, reaching $49.5 \%$. In the group of patients with IL-10<3.6 pg/ $\mathrm{ml}$, more than half of them achieved CR (51.9\%) after treatment, and only $17.6 \%$ of patients relapsed or progressed within one year. Therefore, it is not difficult to speculate that patients with IL-10 $\geq 3.6 \mathrm{pg} / \mathrm{ml}$ may have poor therapeutic effect and are prone to early recurrence (Table 1). Also, the patients with IL-10 $\geq 3.6$ $\mathrm{pg} / \mathrm{ml}$ achieved lower OS and higher early recurrence or progression rate (Figures $\mathbf{2 A}, \mathbf{B}, \mathrm{P}$ value $<0.001$ ). In addition, the cumulative survival rate and cumulative 1-year recurrence or progression rate between the high IL- 6 and low IL- 6 groups and the high IFN $\gamma$ and low IFN $\gamma$ groups were statistically significant (Figures 2C-F, all $\mathrm{P}$ value $<0.001$ ). To our disappointment, they were not independent factors (Tables 3, 4).

In univariate logistic regression analysis, lower $\mathrm{CR}$ rate was related to male, first diagnosis older than 60 years, stage III-IV, B symptoms, bone marrow involvement, IPI $\geq 3$, ECOG $\geq 3$, EBV infection, Extra-nodal $\geq 1$, IL-10 $\geq 3.6 \mathrm{pg} / \mathrm{ml}$, IL- $6 \geq 2.2 \mathrm{pg} / \mathrm{ml}$, IFN $\gamma \geq 3.0 \mathrm{pg} / \mathrm{ml}$, decreased LDH and decreased $\beta 2-\mathrm{MG}$ (Table 2). Nevertheless, in the multivariate logistic regression analysis, only ECOG $\geq 3$, EBV infection, IL-10 $\geq 3.6 \mathrm{pg} / \mathrm{ml}$ were statistically significant (Table 2).

In univariate logistic regression analysis, higher 1-year recurrence or progression rate was associated with stage III-IV, B symptoms, bone marrow involvement, IPI $\geq 3$, ECOG $\geq 3$, decreased albumin, Extra-nodal $\geq 1$, IL- $10 \geq 3.6$ pg/ml, IL- $6 \geq 2.2$ $\mathrm{pg} / \mathrm{ml}$, IFN $\gamma \geq 3.0 \mathrm{pg} / \mathrm{ml}$, decreased SF (Table 3, Figures 2B, D, E). However, only bone marrow involvement ( $\mathrm{OR}=3.799,95 \%$ CI $1.630-8.854, p=0.002)$, ECOG $\geq 3(\mathrm{OR}=5.873,95 \% \mathrm{CI}$ $2.464-13.997, \mathrm{p}<0.001), \mathrm{IL}-10 \geq 3.6 \mathrm{pg} / \mathrm{ml}(\mathrm{OR}=2.008,95 \% \mathrm{CI}$ $0.876-4.601, p=0.009)$ had statistically significant in the multivariate logistic regression analysis (Table 3 ).

\section{Univariate and Multivariate Cox Proportional Hazards Regression Analysis of OS in PTCL Patients}

In our study, recurrence or progression occurred in 67 patients within one year, accounting for $32.7 \%$. The median survival time in the groups with IL- $10 \geq 3.6 \mathrm{pg} / \mathrm{ml}$ and IL- $10<3.6 \mathrm{pg} / \mathrm{ml}$ were 6 months and 26 months (Figure 2A), respectively. Compared with patients with IL-10<3.6 pg/ml, 1-year OS and 2-year OS were lower in patients with IL- $10 \geq 3.6 \mathrm{pg} / \mathrm{ml}$ (80.6 vs. $20.6 \%$, p < $0.001 ; 54.6$ vs. $11.3 \%, \mathrm{p}<0.001$, Figure $2 \mathrm{~A})$. The univariate analysis showed that stage III-IV, B symptoms, bone marrow involvement, IPI $\geq 3$, ECOG $\geq 3$, decreased albumin, EBV infection, Extra-nodal $\geq 1$, HPS, IL- $10 \geq 3.6 \mathrm{pg} / \mathrm{ml}$, IL-6 $\geq 2.2$ $\mathrm{pg} / \mathrm{ml}$, IFN $\gamma \geq 3.0 \mathrm{pg} / \mathrm{ml}$, decreased LDH and decreased serum ferritin were prognostic indicators of OS (Table 4, Figures 2C, E). Then, multivariate analysis was showed that patients 
TABLE 1 | Analysis of clinical and laboratory characteristics of IL-10 stratification in 205 patients with PTCL.

\begin{tabular}{|c|c|c|c|c|}
\hline characteristic & $\begin{array}{c}\text { total } \\
(n=205, \%)\end{array}$ & $\begin{array}{c}\mathrm{IL}-10<3.6 \mathrm{pg} / \mathrm{ml} \\
(\mathrm{n}=108, \%)\end{array}$ & $\begin{array}{c}\text { IL-10 } \\
(n=3.6 \mathrm{pg} / \mathrm{ml} \\
(n=97, \%)\end{array}$ & p Value \\
\hline Age & & & & 0.120 \\
\hline$<60$ years & $127(62.0)$ & $72(66.7)$ & $56(57.7)$ & \\
\hline$\geq 60$ years & 78(38.0) & $36(33.3)$ & $41(42.3)$ & \\
\hline Sex & & & & $0.009^{*}$ \\
\hline Male & $132(64.4)$ & $61(56.5)$ & $71(73.2$ & \\
\hline Female & 73(35.6) & $47(43.5)$ & 26(26.8) & \\
\hline IPI & & & & $0.000^{*}$ \\
\hline $0-2$ & $94(45.9)$ & $70(64.8)$ & $24(24.7)$ & \\
\hline $3-5$ & $111(54.1)$ & $38(35.2)$ & 73(75.3) & \\
\hline ECOG & & & & $0.000^{*}$ \\
\hline $0-2$ & $154(75.1)$ & $94(87.0)$ & 60(61.9) & \\
\hline $3-5$ & $51(24.9)$ & 14(13.0) & $37(38.1)$ & \\
\hline Stage & & & & $0.000^{*}$ \\
\hline$|-| \mid$ & 40(19.5) & 36(33.3) & $4(4.1)$ & \\
\hline III-IV & $165(80.5)$ & $72(66.7)$ & 93(95.9) & \\
\hline B symptoms & & & & $0.000^{*}$ \\
\hline Yes & $113(55.1)$ & $45(41.7)$ & $68(70.1)$ & \\
\hline No & $92(44.9)$ & 63(58.3) & 29(29.9) & \\
\hline $\begin{array}{l}\text { Histological } \\
\text { subtype }\end{array}$ & & & & 0.287 \\
\hline PTCL,NOS & $57(27.8)$ & 36(33.3) & 23(23.7) & \\
\hline ENKTL & 69(33.6) & 36(33.3) & $31(32.0)$ & \\
\hline AITL & $44(21.5)$ & $20(18.5)$ & $24(24.7)$ & \\
\hline ALCL,ALK+ & $16(7.8)$ & $8(7.4)$ & $8(8.3)$ & \\
\hline ALCL,ALK- & $10(4.9)$ & $6(5.6)$ & $4(4.1)$ & \\
\hline Others ${ }^{\#}$ & $9(4.4)$ & $2(1.9)$ & $7(7.2)$ & \\
\hline Bone marrow Involvement & & & & $0.000^{\star}$ \\
\hline Yes & 68(33.2) & 23(78.7) & $45(46.4)$ & \\
\hline No & $137(66.8)$ & $85(21.3)$ & $52(53.6)$ & \\
\hline Albumin(g/l) & & & & $0.000^{\star}$ \\
\hline$<35$ & 58(28.3) & $12(11.1)$ & $46(47.4)$ & \\
\hline$\geq 35$ & $147(71.7)$ & 96(88.9) & $51(52.6)$ & \\
\hline HPS & & & & $0.000^{*}$ \\
\hline Yes & $24(11.7)$ & $3(2.8)$ & 21(21.6) & \\
\hline No & 181(88.3) & 105(97.2) & 76(78.4) & \\
\hline Elevated IL-6 level & & & & $0.000^{*}$ \\
\hline Yes & $139(67.8)$ & $60(55.6)$ & 79(81.4) & \\
\hline No & $66(32.2)$ & $48(44.4)$ & 18(18.6) & \\
\hline Elevated IFN $\gamma$ level & & & & $0.000^{*}$ \\
\hline Yes & $78(38.0)$ & 23(21.3) & $55(56.7)$ & \\
\hline No & $127(62.0)$ & $85(78.7)$ & 42(43.3) & \\
\hline EBV & & & & $0.028^{*}$ \\
\hline Negative & $85(41.5)$ & $52(48.1)$ & 33(34.0) & \\
\hline Positive & $120(58.5)$ & $56(51.9)$ & $64(66.0)$ & \\
\hline Extra-nodal Involvement & & & & $0.000^{*}$ \\
\hline$\leq 1$ & $107(52.2)$ & $71(65.7)$ & $36(37.1)$ & \\
\hline$>1$ & $98(47.8)$ & $37(34.3)$ & $61(62.9)$ & \\
\hline Elevated LDH level & & & & $0.000^{*}$ \\
\hline Yes & 136(66.3) & $60(55.6)$ & 76(78.4) & \\
\hline No & 69(33.7) & $48(44.4)$ & 21(21.6) & \\
\hline Elevated $\beta 2-M G$ level & & & & $0.000^{\star}$ \\
\hline Yes & 131(63.9) & $55(50.9)$ & $76(78.4)$ & \\
\hline No & $74(36.1)$ & $53(49.1)$ & $21(21.6)$ & \\
\hline Elevated SF level & & & & $0.004^{\star}$ \\
\hline Yes & $108(52.7)$ & $47(43.5)$ & $61(62.9)$ & \\
\hline No & $97(47.3)$ & $61(56.5)$ & $36(37.1)$ & \\
\hline Attainment of CR & & & & $0.000^{\star}$ \\
\hline Yes & $70(34.1)$ & $56(51.9)$ & $14(14.4)$ & \\
\hline No & $135(65.9)$ & $52(48.1)$ & 83(85.6) & \\
\hline
\end{tabular}


TABLE 1 | Continued

\begin{tabular}{lccc}
\hline characteristic & $\begin{array}{c}\text { total } \\
(\mathbf{n = 2 0 5 , \% )}\end{array}$ & $\begin{array}{c}\text { IL-10<3.6pg/ml } \\
\text { (n=108, \%) }\end{array}$ & $\begin{array}{c}\text { IL-10 } \\
\text { (n=3.67, \%) }\end{array}$ \\
\hline $\begin{array}{l}\text { Recurrence/progress in one year } \\
\text { Yes }\end{array}$ & $67(32.7)$ & $19(17.6)$ & $48(49.5)$ \\
No & $138(67.3)$ & $89(82.4)$ & $49(50.5)$
\end{tabular}

\# others: 3 cases of MEITL, 1 case of T-LGLL, 2 cases of SPTCL, 2 cases of MF/SS, 1 case of HSTCL; CR, complete response.

*Significantly different.

The classification variables are expressed by frequency and percentage. $(n, \%)$.

with poor OS had ECOG $\geq 3$ ( $\mathrm{HR}=4.314,95 \%$ CI 2.462-7.559, $\mathrm{p}<0.001)$, Extra-nodal $\geq 1(\mathrm{HR}=2.126,95 \% \mathrm{CI} 1.142-3.958, \mathrm{p}=$ $0.017)$, IL-10 $\geq 3.6 \mathrm{pg} / \mathrm{ml}(\mathrm{HR}=6.428,95 \%$ CI 3.369-12.266, $\mathrm{p}<$ $0.001)$, and IL-6 $\geq 2.2 \mathrm{pg} / \mathrm{ml}(\mathrm{HR}=2.050,95 \%$ CI $1.122-3.745$, $\mathrm{p}=0.020)$.

Thus, it can be seen that among the three cytokines included in our studies, only IL-10 was significant and independent prognostic factor in both univariate and multivariate analyses of treatment response, survival, and early recurrence in PTCL patients. IL-6 had an independent effect on OS in multivariate analyses as well. The results of Cox regression analysis were present in Table 4.

\section{DISCUSSION}

Benefit from the oceans of studies about tumor microenvironment, tremendous progress has been made in predicting the prognosis of PTCL. Nevertheless, poor response, high mortality, and relapse remain primary challenges, so new

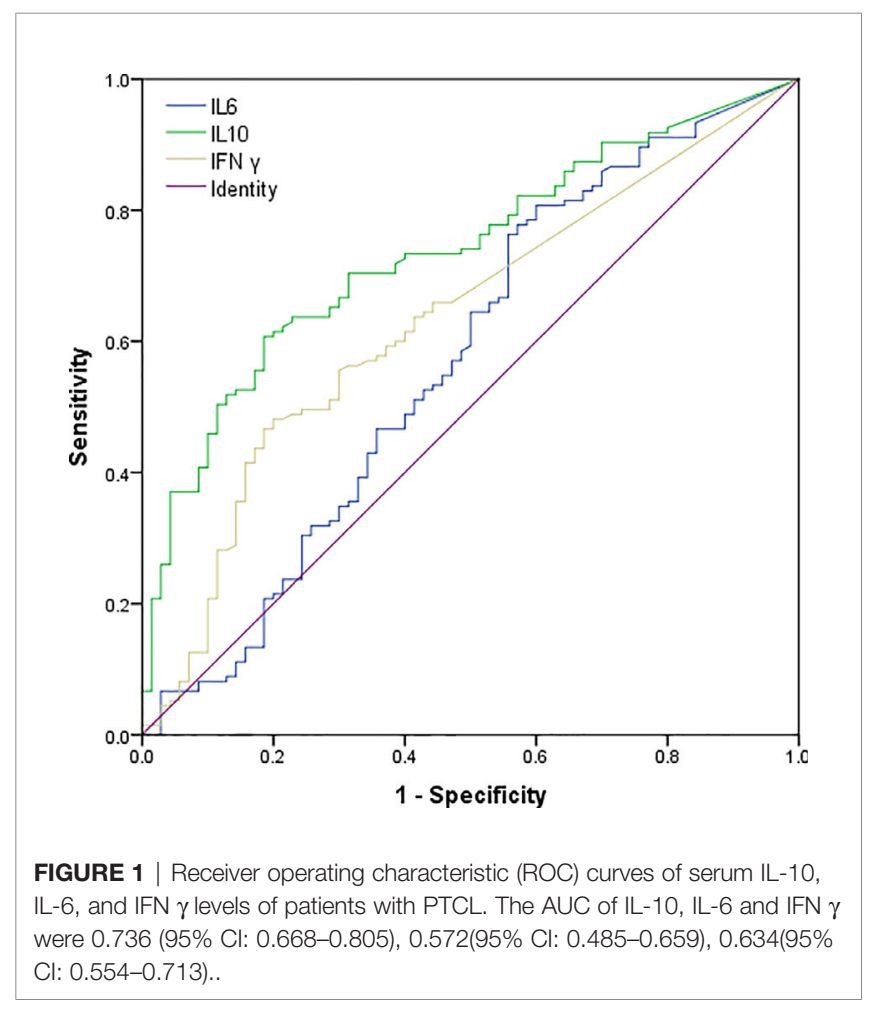

prognostic factors need to be explored to further predict and improve the prognosis of PTCL patients. According to the established tumor models, Sato T et al. found that IL-10 has tumor-promoting and anti-tumor effects in vivo (14). Herein, we retrospectively analyzed six cytokines of 205 patients with PTCL and discovered that patients with IL-10 $\geq 3.6 \mathrm{pg} / \mathrm{ml}$ had both low $\mathrm{CR}$ rate, low OS rate but high 1-year recurrence or progression rate as an independent effect in multivariate analyses. Therefore, from our retrospective clinical studies, IL-10 may play a role as pro-tumor effects in vivo.

C. Andrew Stewart et al. observed that the majority of tumorassociated IL-10 was produced by activated Tregs. Components of the type I IFN signaling pathway, including Ifnar1, Stat1 and Stat2, were essential for the accumulation and activation of Tregs and production of IL-10 (15). In cancer-related preclinical and therapeutic models, Tregs limits the production of Th1 responses that drive CD8 $+\mathrm{T}$ cells and IFN $\gamma$ dependent anti-tumor immunity $(16,17)$. Th17 cells occur in most human tumors frequently. Th17 related inflammation may lead to tumor growth or autoimmunity. The production of IL-10 limits the quantities and activity of Th17 cells in tumors, which promotes the growth of tumors (18).

The poor response of immunotherapy in most tumors were bound up with tumor-associated macrophages (TAM), Tregs and myeloid-derived suppressor cells (MDSCs). MDSCs can induce the production of Tregs and lead Tregs to tumor tissues, thus promoting the production of IL-10 (19). TAM were related to the poor clinical prognosis of various human tumors by promoting angiogenesis, local invasion and metastasis (20-23). It has been confirmed that the growth and survival of malignant $\mathrm{T}$ cells depend on alternately activated (M2) macrophages in the microenvironment, and the growth of alternately activated (M2) macrophages was affected by the presence of TAMs $(4,24)$. Sam T. Hwang found that alternately activated (M2) macrophages can affect the polarization of undifferentiated macrophages in the way specified (25). In a mouse model study, M2 macrophages can increase the secretion of IL-10 by macrophages which is necessary for the maximum growth of human cutaneous T-cell lymphoma (25). Kim SJ and Ham JS analyzed the serum cytokines and CD68and CD163- positive macrophage in tumor tissue of 37 AITL patients after CHOP chemotherapy, and found that high IL-10 and M2 macrophage tissue infiltration all indicated low OS and poor response to treatment (26). In subsequent studies, this team further tested 34 cytokines in 121 patients with PTCL, and analyzed the correlation between overall survival rate and complete remission rate. They found that patients with AITL 


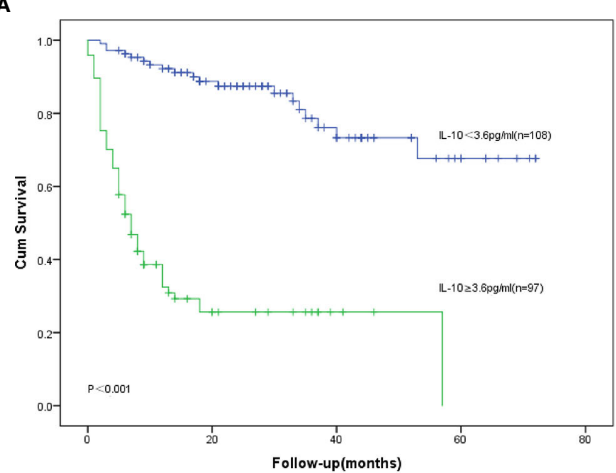

C

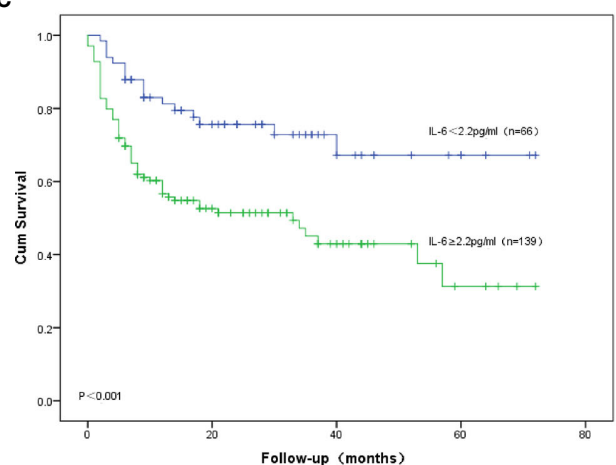

E

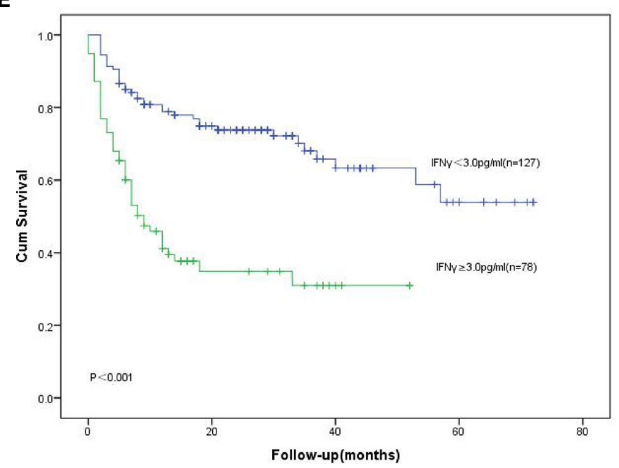

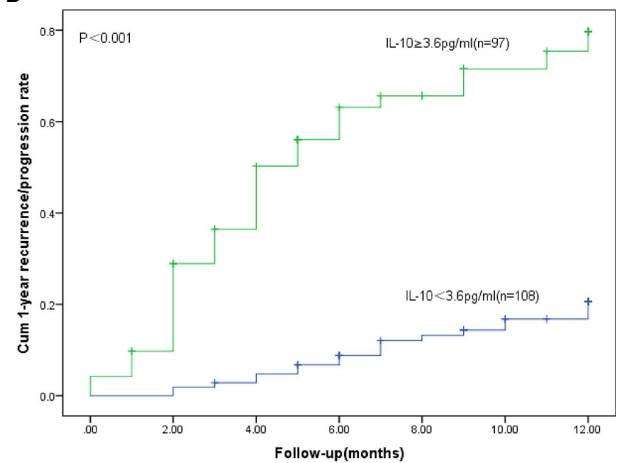
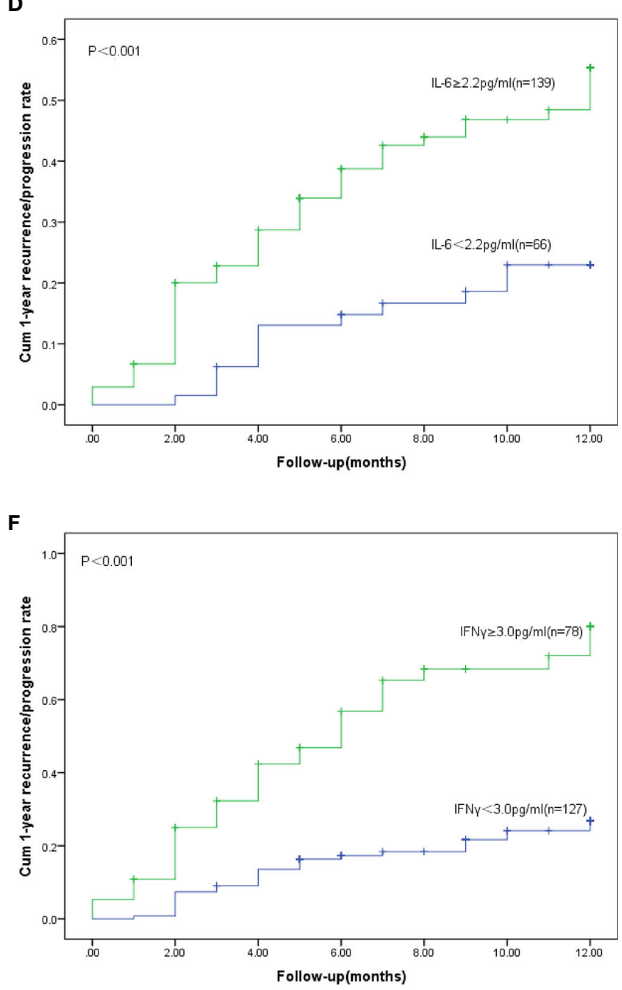

FIGURE 2 | OS: Overall survival. (A) OS for different serum levels of IL-10; (B) Recurrence/progression in one year for different serum levels of IL-10. (C) OS for different serum levels of IL-6; (D) Recurrence/progression in one year for different serum levels of IL-6; (E) OS for different serum levels of IFN $\gamma$; (F) Recurrence/ progression in one year for different serum levels of IFN $\gamma$.

had higher serum cytokine levels, and IL-10 levels higher than 3.8 $\mathrm{pg} / \mathrm{ml}$ were associated with adverse outcomes, which was very close to our cut-off value. In addition to IL-10, IFN $\gamma$, IL-8, IL-17, IL-23, monocyte chemoattractant protein-1 and macrophage inflammatory protein-1 $\beta$, and RANTES negatively also have negative effects on clinical prognosis in patients with ALKanaplastic large cell lymphoma (27). Li Li and Zhang Jun found that the released IL-10 made the JAK2/STAT3 pathway sensitive, leading to STAT3-induced PD-L1 expression (28). At the same time, they confirmed PD-L1 signaling network in 2 main 428 and 350 DLBCL cohorts, and showed a significant correlation among IL-10, STAT3, and PD-L1 (28). H. Dean et al. conducted genetic analysis of 20 single nucleotide polymorphisms (SNPs) in IL-10 and TNF/LTA loci in three independent case-control studies (2,635 cases and 4,234 controls), discovered IL-10 rs1800896 was related to DLBCL, as well as T-cell lymphoma (29). It was confirmed that genetic variations of immune-related genes (such as IL-10) were related to the occurrence of T-cell lymphoma in Asian populations (29). To sum up, it had been proved that IL-10 was related to the prognosis of malignant $\mathrm{T}$-cell lymphoma in both gene and molecular studies and animal experimental studies. It promoted tumor cells to evade immune surveillance by regulating antigen presentation and immune cell differentiation (30). Mona R. Hassuneh et al. used LSA (a T-cell lymphoma cell line 
TABLE 2 | Univariate and multivariate logistic regression models of complete response (CR) in PTCL patients.

\begin{tabular}{|c|c|c|c|c|c|c|}
\hline Parameters & \multicolumn{3}{|c|}{ Univariate analysis } & \multicolumn{3}{|c|}{ Multivariate analysis } \\
\hline Sex, Male & 0.472 & $0.260-0.858$ & $0.014^{*}$ & & & \\
\hline Stage, III-IV & 5.107 & $2.447-10.658$ & $<0.001^{\star}$ & & & \\
\hline B symptoms & 2.128 & $1.184-3.827$ & $0.012^{\star}$ & & & \\
\hline Bone marrow Involvement & 3.014 & $1.507-6.030$ & $0.002^{*}$ & & & \\
\hline EBV,Positive & 2.667 & $1.473-4.827$ & $0.001^{*}$ & 2.419 & $1.209-4.840$ & $0.013^{*}$ \\
\hline Extra-nodal, $>1$ & 2.119 & $1.169-3.841$ & $0.013^{\star}$ & & & \\
\hline IL-10 $\geq 3.6 \mathrm{pg} / \mathrm{ml}$ & 6.385 & 3.233-12.609 & $<0.001^{*}$ & 2.973 & $1.344-6.578$ & $0.015^{\star}$ \\
\hline $\mathrm{IL}-6 \geq 2.2 \mathrm{pg} / \mathrm{ml}$ & 2.271 & $1.236-4.175$ & $0.008^{\star}$ & & & \\
\hline IFN- $\gamma \geq 3.0 \mathrm{pg} / \mathrm{ml}$ & 3.606 & $1.834-7.089$ & $<0.001^{\star}$ & & & \\
\hline Elevated LDH & 2.230 & $1.220-4.078$ & $0.009^{\star}$ & & & \\
\hline
\end{tabular}

$\mathrm{OR}$, odds ratio; $\mathrm{Cl}$, confidence interval.

*Significantly different.

TABLE 3 | Univariate and multivariate logistic regression models for recurrence or progression within one year in PTCL patients.

\begin{tabular}{|c|c|c|c|c|c|c|}
\hline Parameters & \multicolumn{3}{|c|}{ Univariate analysis } & \multicolumn{3}{|c|}{ Multivariate analysis } \\
\hline Stage,III-IV & 5.559 & $1.888-16.364$ & $0.002^{*}$ & & & \\
\hline Bone marrow Involvement & 5.235 & $2.774-9.880$ & $<0.001^{*}$ & 3.799 & $1.630-8.854$ & $0.002^{*}$ \\
\hline IPI,3-5 & 3.008 & $1.605-5.636$ & $0.001^{*}$ & & & \\
\hline ECOG,3-5 & 8.340 & $4.108-16.931$ & $<0.001^{\star}$ & 5.873 & $2.464-13.997$ & $<0.001^{*}$ \\
\hline HPS & 4.135 & $1.703-10.037$ & $0.002^{*}$ & & & \\
\hline $\mathrm{IL}-10 \geq 3.6 \mathrm{pg} / \mathrm{ml}$ & 4.589 & 2.431-8.663 & $<0.001^{*}$ & 2.008 & $0.876-4.601$ & $0.009^{*}$ \\
\hline IL-6 $2.2 .2 \mathrm{pg} / \mathrm{ml}$ & 2.590 & $1.291-5.194$ & $0.007^{\star}$ & & & \\
\hline IFN $\gamma \geq 3.0 \mathrm{pg} / \mathrm{ml}$ & 3.536 & $1.920-6.512$ & $<0.001^{\star}$ & & & \\
\hline Elevated SF & 1.833 & $1.009-3.330$ & $0.047^{\star}$ & & & \\
\hline
\end{tabular}

$\mathrm{OR}$, odds ratio; $\mathrm{Cl}$, confidence interval.

*Significantly different.

TABLE 4 | Univariate and multivariate Cox proportional hazard regression models for overall survival (OS) in PTCL patients.

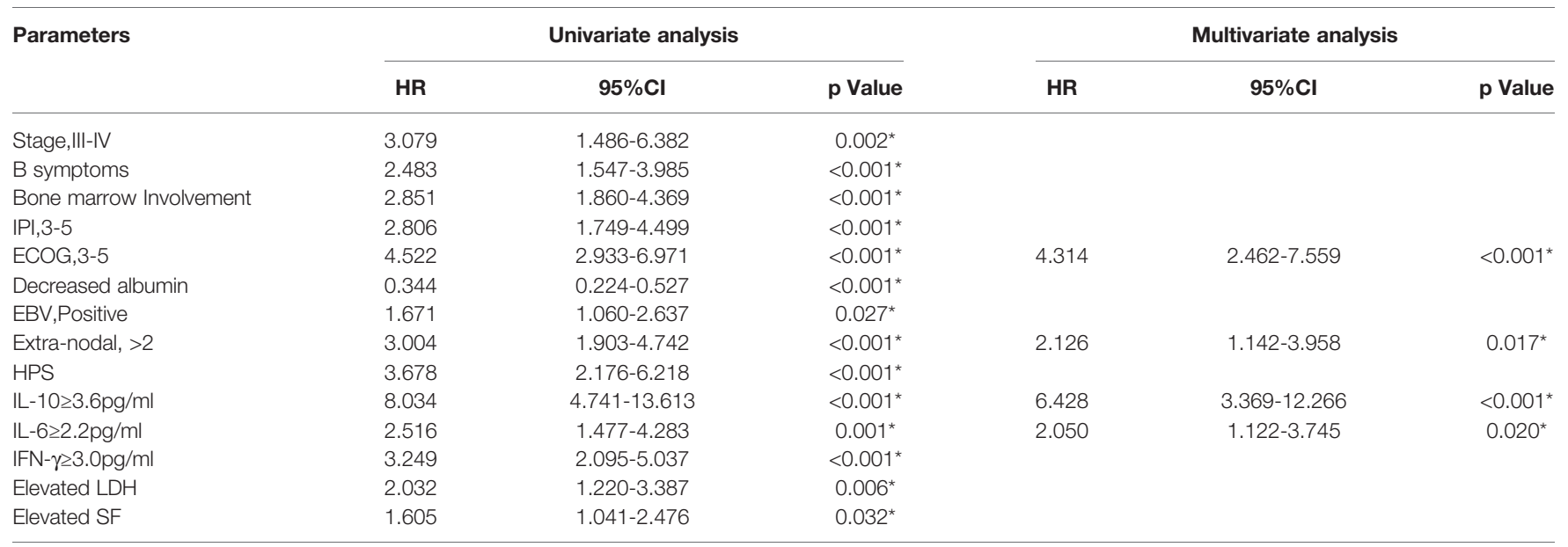

$H R$, hazard ratio; $\mathrm{Cl}$, confidence interval. *Significantly different. 
expressing IL-10) to study the role of IL-10 in tumorigenesis. Interestingly, the administration of anti-IL-10 antibodies significantly inhibited the growth of tumors in LSA (31).

Previously, stage was well recognized as having a prognostic impact in PTCL, and it had been included in previously reported indices in subsequent studies (32), indicating that it was highly significant predictor of OS. In our study, stage III-IV was associated with low response rate, early recurrence and poor OS, which was consistent with previous studies. In Table $\mathbf{1}$, it is easy to find that in patients with IL-10 levels higher than $3.6 \mathrm{pg} /$ $\mathrm{ml}$, the proportion of stage III-IV is significantly higher than that of stage I-II (95.9 vs $4.1 \%)$. It is further suggested that the increase of IL-10 levels might be related to distant metastasis and immune escape.

IL-10 has strong immunosuppression. It inhibits the proliferation of $\mathrm{T}$ cells (33). Thus, overexpression of IL-10 by PTCL lymphoma cells may damage the host's immune system, resulting in immunosuppression and tumor escape. At the same time, it will also provide a selective survival advantage for the PTCL cells in the host. What is more, serum IL-10 concentration is also an important prognostic factor for various tumors, such as diffuse large B-cell lymphoma (DLBCL) and adult T-cell leukemia/lymphoma (ATL) $(12,20,34)$. Our study proved that IL-10 plays an important role in the treatment response, survival and early recurrence or progression of PTCL patients. In multivariate regression analysis, patients with $\mathrm{IL}-10 \geq 3.6 \mathrm{pg} / \mathrm{ml}$ had a lower CR rate and a higher recurrence rate. In univariate and multivariate survival analysis, patients with IL- $10 \geq 3.6 \mathrm{pg} / \mathrm{ml}$ had poorer OS. To the best of our knowledge, this retrospective clinical study is the first to confirm the effect of IL-10 on the treatment response, survival, and early recurrence of Chinese PTCL patients. Insaki Atsushi et al. analyzed the serum IL-10 levels in 94 cases of ATL and found that high IL-10 levels were an important adverse prognostic factor in ATL. However, the critical value of IL-10 in our study is different from the results of Atsushi Inagaki et al. (34). They mainly target ATL patients between the ages of 38-89 and the number of cases in their study is less than 100, however our study contained the five major PTCL subtypes and the five rare subtypes of MEITL, T-LGLL, SPTCL, MF/SS, and HSTCL with age range of 18-79 years old, and we have more than twice as many cases as they have. Perhaps, the different number of cases, disease types and inclusive criteria that led to the different cutoff values. Similarly, IL-10 is still an independent prognostic factor for survival and early recurrence in patients with PTCL.

In addition, we were surprised to find that there was a gender difference between the high IL-10 group and the low IL-10 group. The proportion of female patients was significantly lower than the male patients in high IL-10 group (26.8 vs $73.2 \%$ ), and the treatment response of female patients was better than that of the male (Table 2). It aroused our interest, and we specially reviewed some similar previous studies. Previous studies had shown the differences in immune function between age and gender. These differences were believed to be caused by hormone discrepancies, especially the loss of estradiol caused the reversal of immune response in elderly females (35). Interestingly, the inhibitory effect of female derived MDSCs on T cells proliferation were stronger than that of male. Transplantation of female derived MDSCs significantly increased the frequency and absolute number of Tregs and CD4 + IL-10 + T cells (36). However, in tumor environment, MDSCs not only have characteristics of M2 macrophages (such as the expression of arginase-1 and NOS2), but also play a role as the progenitor cells of tumor associated macrophages. Moreover, MDSCs can further regulate the cytotoxicity mediated by macrophages $(37,38)$.

Hemophagocytic syndrome (HPS) is an immune-mediated life-threatening disease that affects $1 \%$ of adults with hematological cancers, and its prevalence rises to $20 \%$ in patients with NHL, especially PTCL (39). Qi An et al. found that median serum concentrations of IFN $\gamma$ and IL-10 were significantly higher in children with HPS compared to healthy controls (40). In our study, there were 24 patients with HPS, accounting for $11.7 \%$, and the median serum of IL-10 and IFN $\gamma$ were higher than the patients without HPS (54.02 vs. $2.70 \mathrm{pg} / \mathrm{ml}$, $\mathrm{p}<0.001 ; 12.42$ vs. $1.02 \mathrm{pg} / \mathrm{ml}, \mathrm{p}<0.001)$. Importantly, although the OS of PTCL patients with HPS decreased significantly, HPS was not an independent predictor for OS of PTCL patients after univariate and multivariate analysis in our study.

Our study still has some limitations. Firstly, the retrospective study may be biased in the selection of patients. Secondly, the dynamic changes of patients during treatment did not take into account during analysis. Thirdly, due to the limitation of the number of cases, the conclusions of this study are only verified in three common subtypes of PTCL-NOS, ENKTL, and AITL. Therefore, more in-depth studies are needed to confirm the role of IL-10 in the prognosis of patients with PTCL.

\section{CONCLUSIONS}

All in all, increased serum levels of IL-10 at diagnosis is related to the survival and early recurrence of PTCL patients. IL-10 $\geq 3.6$ $\mathrm{pg} / \mathrm{ml}$ is significantly correlated with lower CR rate, higher recurrence rate and lower OS rate. Furthermore, univariate and multivariate analysis indicated that IL-10 $\geq 3.6 \mathrm{pg} / \mathrm{ml}$ is an independent prognostic factor. In short, the serum level of IL10 in the peripheral blood at the initial stage can be added to the prognostic tool to play its prognostic role in PTCL. In addition, the determination of serum cytokine levels is quick and convenient. Only a small amount of serum samples can be used to complete the detection. This is very useful to help us formulate different treatment strategies for individuals with PTCL, because it can predict the prognosis before treatment. In the near future, IL-10 inhibitors or antagonists may become a new method of Immunotargeting therapy for PTCL patients.

\section{DATA AVAILABILITY STATEMENT}

The raw data supporting the conclusions of this article will be made available by the authors, without undue reservation. 


\section{ETHICS STATEMENT}

Written informed consent was obtained from the individual(s) for the publication of any potentially identifiable images or data included in this article.

\section{AUTHOR CONTRIBUTIONS}

WX designed the study. YZ, YLZ, LS, YS, HS, MZ, XY, and JJ collected the patients' material. YZ and YLZ analyzed data and

\section{REFERENCES}

1. American Society of Hematology. A clinical evaluation of the Inernational Lymphoma Study Group classification of non-Hodgkin's lymphoma. The Non-Hodgkin's Lymphoma Classification Project. Blood (1997) 89:3909-18. doi: 10.1182/blood.V89.11.3909

2. Shi Y. Current status and progress of lymphoma management in China. Int J Hematol (2018) 107(4):405-12. doi: 10.1007/s12185-018-2404-8

3. Swerdlow SH, Campo E, Harris NL. World Health Organization classification of tumors of haematopoietic and lymphold tissues. Lyon, France: IARC (2016).

4. Wilcox RA, Wada DA, Ziesmer SC, Elsawa SF, Comfere NF, Dietz AB, et al. Monocytes promote tumor cell survival in T-cell lymphoproliferative disorders and are impaired in their ability to differentiate into mature dendritic cells. Blood (2009) 114(14):2936-44. doi: 10.1182/blood-2009-05220111

5. Staples KJ, Smallie T, Williams LM, Foey A, Burke B, Foxwell BMJ, et al. IL-10 Induces IL-10 in Primary Human Monocyte-Derived Macrophages via the Transcription Factor Stat3. J Immunol (2007) 178:4779-85. doi: 10.4049/ jimmunol.178.8.4779

6. Iqbal J, Wright G, Wang C. Gene expression signatures delineate biological and prognostic subgroups in peripheral T-cell lymphoma. Blood (2014) 123:2915-23. doi: 10.1182/blood-2013-11-536359

7. Wang T, Feldman AL, Wada DA, Lu Y, Polk A, Briski R, et al. GATA-3 expression identifies a high-risk subset of PTCL, NOS with distinct molecular and clinical features. Blood (2014) 123:3007-15. doi: 10.1182/blood-2013-12-544809

8. Xua G, Wang F. Associations of polymorphisms in interleukins with susceptibility to breast cancer: Evidence from a meta-analysis. Cytokine (2020) 130:154988. doi: 10.1016/j.cyto.2020.154988

9. Lombardi Pereira AP, Paiva Trugilo K, Okuyama NCM, Mota Sena M, D'Oliveira Couto-Filho J, Watanabe MAE, et al. IL-10 c.-592C>A (rs1800872) polymorphism is associated with cervical cancer. J Cancer Res Clin Oncol (2020) 146(8):1971-8. doi: 10.1007/s00432-020-03256-0

10. Zhong-Wu LU, Hu J-Q, Liu W-L, Wen D, Wei W-J, Wang Y-L, et al. IL-10 restores $\mathrm{MHC}$ class I expression and interferes immunity in papillary thyroid cancer with Hashimoto's thyroiditis. Endocrine Soc (2020).

11. Sakai Y, Rezano A, Okada S, Ohtsuki T, Kawashima Y, Tsukamoto T, et al. A Novel Cytological Model of B-Cell/Macrophage Biphenotypic Cell Hodgkin Lymphoma in Ganp-Transgenic Mice. Cancers (Basel) (2020) 12(1):204. doi: $10.3390 /$ cancers 12010204

12. Yi JH, Yoon SE, Ryu KJ, Ko YH, Kim WS, Kim SJ. Pre-treatment serum IL-10 predicts the risk of secondary central nervous system involvement in patients with diffffuse large B-cell lymphoma. Cytokine (2020) 129:155048. doi: 10.1016/j.cyto.2020.155048

13. Altman DG, McShane LM, Sauerbrei W, Taube SE. Reporting Recommendations for Tumor Marker Prognostic Studies (REMARK): Explanation and Elaboration. PloS Med (2012) 9(5):e1001216. doi: 10.1371/ journal.pmed.1001216

14. Sato T, Terai M, Tamura Y, Alexeev V, Mastrangelo MJ, Selvan SR. Interleukin 10 in the tumor microenvironment: a target for anticancer immunotherapy. Immunol Res (2011) 51:170-82. doi: 10.1007/s12026-011-8262-6

15. Andrew Stewart C, Muller W, Trinchieri G. Interferon-dependent IL-10 production by Tregs limits tumor Th17 inflammation. J Clin Invest (2013) 123(11):4859-74. doi: 10.1172/JCI65180 wrote the paper. All authors contributed to the article and approved the submitted version.

\section{ACKNOWLEDGMENTS}

The authors thank the practitioners who helped to collect and sort out the patient' information and follow-up, especially Prof. Xin Huang from the Institute of Hematology, Zhejiang University, for his support in this study.

16. Teng MW, Ngiow SF, von Scheidt B, McLaughlin N, Sparwasser T, Smyth MJ. Conditional regulatory $\mathrm{T}$-cell depletion releases adaptive immunity preventing carcinogenesis and suppressing established tumor growth. Cancer Res (2010) 70(20):7800-9. doi: 10.1158/0008-5472.CAN-10-1681

17. Teng MW, Ritchie DS, Neeson P, Smyth MJ. Biology and clinical observations of regulatory $\mathrm{T}$ cells in cancer immunology. Curr Top Microbiol Immunol (2011) 344:61-95. doi: 10.1007/82_2010_50

18. Wilke CM, Wang L, Wei S, Kryczek I, Zou W. Endogenous interleukin-10 constrains Th17 cells in patients with inflammatory bowel disease. J Transl Med (2011) 9:217. doi: 10.1186/1479-5876-9-217

19. Du J, Sun X, Song Y. The study of CD14+HLA-DR-/low myeloid-drived suppressor cell (MDSC) in peripheral blood of peripheral T-cell lymphoma patients and its biological function. Cell Mol Biol (Noisy-le-grand) (2017) 63 (3):62-7. doi: $10.14715 / \mathrm{cmb} / 2017.63 .3 .12$

20. Malesci A, Bianchi P, Celesti G, Basso G, Marchesi F, Grizzi F, et al. Tumorassociated macrophages and response to 5-fluorouracil adjuvant therapy in stage III colorectal cancer. Oncoimmunology (2017) 6(12):e1342918. doi: 10.1080/2162402X.2017.1342918

21. Qiu SQ, Waaijer SJH, Zwager MC, de Vries EGE, van der Vegt B, Schröder CP. Tumor-associated macrophages in breast cancer: Innocent bystander or important player? Cancer Treat Rev (2018) 70):178-89. doi: 10.1016/j.ctrv.2018.08.010

22. Futagbi G, Gyan B, Nunoo H, Tetteh JKA, Welbeck JE, Renner LA, et al. High Levels of IL-10 and CD4+CD25hi+ Treg Cells in Endemic Burkitt's Lymphoma Patients. Biomedicines (2015) 3:224-36. doi: 10.3390/ biomedicines 3030224

23. Ryder M, Ghossein RA, Ricarte-Filho JC, Knauf JA, Fagin JA. Increased density of tumor-associated macrophages is associated with decreased survival in advanced thyroid cancer. Endocr Relat Cancer (2008) 15(4):1069-74. doi: 10.1677/ERC-08-0036

24. Wu X, Schulte BC, Zhou Y. Depletion of M2-like tumor-associated macrophages delays cutaneous T-cell lymphoma development in vivo. J Invest Dermatol (2014) 134:2814-22. doi: 10.1038/jid.2014.206

25. Wu X, Hsu DK, Wang K-H, Huang Y, Mendoza L, Zhou Y, et al. IL-10 is overexpressed in human cutaneous T-cell lymphoma and is required for maximal tumor growth in a mouse model. Leuk Lymphoma. (2019) 60 (5):1244-52. doi: 10.1080/10428194.2018.1516037

26. Ham JS, Park HY, Ryu KJ, Ko YH, Kim WS, Kim SJ. Elevated serum interleukin-10 level and M2 macrophage infiltration are associated with poor survival in angioimmunoblastic T-cell lymphoma. Oncotarget (2017) 8 (44):76231-40. doi: 10.18632/oncotarget.19301

27. Yi JH, Ryu KJ, Ko YH, Kim WS, Kim SJ. Profiles of serum cytokines and their clinical implications in patients with peripheral T-cell lymphoma. Cytokine (2019) 113:371-9. doi: 10.1016/j.cyto.2018.10.009

28. Li L, Zhang J, Pham LV. B-cell receptor-mediated NFATc1 activation induces IL-10/STAT2/PD-L1 signaling in diffuse large B-cell lymphoma. Blood (2018) 132(17):1805-17. doi: 10.1182/blood-2018-03-841015

29. Dean Hosgood III H, Au W-Y, Kim HN, Liu J, Hu W, Tse J, et al. IL-10 and TNF variants and risk of non-Hodgkin lymphoma among three Asian populations. Int J Hematol (2013) 97:793-9. doi: 10.1007/s12185-013-1345-5

30. Mantovani A, Sozzani S, Locati M. Macrophage polarization: tumorassociated macrophages as a paradigm for polarized M2 mononuclear phagocytes. Trends Immunol (2002) 23:549-55. doi: 10.1016/S1471-4906 (02)02302-5 
31. Hassuneh MR, Nagarkatti M, Nagarkatti PS. Role of interleukin-10 in the regulation of tumorigenicity of a T cell lymphoma. Leuk Lymphoma (2013) 54 (4):827-34. doi: 10.3109/10428194.2012.726721

32. Weisenburger DD, Savage KJ, Harris NL, Gascoyne RD, Jaffe ES, MacLennan KA, et al. Peripheral T-cell lymphoma, not otherwise specifified: a report of 340 cases from the International Peripheral T-cell Lymphoma Project. Blood (2011) 117:3402-8. doi: 10.1182/blood-2010-09-310342

33. Taga K, Mostowski H, Tosato G. Human interleukin-10 can directly inhibit T-cell growth. Blood (1993) 81:2964-71. doi: 10.1182/blood.V81.11.2964. bloodjournal81112964

34. Inagaki A, Ishida $\mathrm{T}$, Ishii $\mathrm{T}$, Komatsu $\mathrm{H}$, lida S, Ding J, et al. Clinical signifificance of serum Th1-, Th2- and regulatory T cells-associated cytokines in adult T-cell leukemia/lymphoma: High Interleukin-5 and -10 levels are signifificant unfavorable prognostic factors. Int J Cancer (2006) 118:3054-61. doi: 10.1002/ijc.21688

35. Kahlke V, Angele MK, Ayala A, Schwacha MG, Cioffi WG, Bland KI, et al. Immune dysfunction following traumahemorrhage: influence of gender and age. Cytokine (2000) 12:69-77. doi: 10.1006/cyto.1999.0511

36. Su N, Yue Y, Xiong S. Monocytic myeloid-derived suppressor cells from females, but not males, alleviate CVB3- induced myocarditis by increasing regulatory and CD4+IL-10+ T cells. Sci Rep (2016) 6:22658. doi: 10.1038/srep22658

37. Youn JI, Gabrilovich DI. The biology of myeloid-derived suppressor cells: the blessing and the curse of morphological and functional heterogeneity. Eur J Immunol (2010) 40:2969-75. doi: 10.1002/eji.201040895
38. Maeda A, Eguchi H, Nakahata K, Lo P-C, Yamanaka K, Kawamura T, et al. Monocytic MDSCs regulate macrophage-mediated xenogenic cytotoxicity. Transpl Immunol (2015) 33:140-5. doi: 10.1016/j.trim.2015.07.002

39. Ramos-Casals M, Brito-Zerón P, López-Guillermo A, Khamashta MA, Bosch X. Adult haemophagocytic syndrome. Lancet (2014) 383:1503-16. doi: 10.1016/ S0140-6736(13)61048-X

40. An Q, Hu S-Y, Xuan C-M, Jin M-W, Ji Q, Wang Y. Interferon gamma and interleukin 10 polymorphisms in Chinese children with hemophagocytic lymphohistiocytosis. Pediatr Blood Cancer (2017) 64:9. doi: 10.1002/ pbc. 26505

Conflict of Interest: The authors declare that the research was conducted in the absence of any commercial or financial relationships that could be construed as a potential conflict of interest.

Copyright $\odot 2020$ Zhang, Zheng, Shou, Shi, Shen, Zhu, Ye, Jin and Xie. This is an open-access article distributed under the terms of the Creative Commons Attribution License (CC BY). The use, distribution or reproduction in other forums is permitted, provided the original author(s) and the copyright owner(s) are credited and that the original publication in this journal is cited, in accordance with accepted academic practice. No use, distribution or reproduction is permitted which does not comply with these terms. 